\title{
Mesenchymal Stem Cell-Derived Exosomes: Hope for Spinal Cord Injury Repair
}

\author{
Zhihua Ren, ${ }^{1,2, *}$ Yao Qi, ${ }^{2, *}$ Siyuan Sun, ${ }^{1,3}$ Yuanyuan Tao, ${ }^{1,2}$ and Riyi Shi ${ }^{1}$
}

Spinal cord injury (SCI) is a devastating medical condition with profound social and economic impacts. Although research is ongoing, current treatment options are limited and do little to restore functionality. However, recent studies suggest that mesenchymal stem cell-derived exosomes (MSC-exosomes) may hold the key to exciting new treatment options for SCI patients. MSCs are self-renewing multipotent stem cells with multi-directional differentiation and can secrete a large number of exosomes (vesicles secreted into the extracellular environment through endocytosis, called MSC-exosomes). These MSC-exosomes play a critical role in repairing SCI through promoting angiogenesis and axonal growth, regulating inflammation and the immune response, inhibiting apoptosis, and maintaining the integrity of the blood-spinal cord barrier. Furthermore, they can be utilized to transport genetic material or drugs to target cells, and their relatively small size makes them able to permeate the blood-brain barrier. In this review, we summarize recent advances in MSC-exosome themed SCI treatments and cell-free therapies to better understand this newly emerging methodology.

Keywords: spinal cord injury, mesenchymal stem cells, exosomes, cell-free therapy

\section{Introduction}

I N RECENT YEARS, the number of patients with spinal cord injury (SCI) has increased gradually. Because of the high medical expenses, complex conditions, treatment challenges, various complications, and low cure rate associated with SCI, it imposes a heavy burden on patients, their families, and society, making this condition a major challenge for researchers.

Stem cell therapy as a new strategy for the treatment of SCI has attracted much attention recently [1]. Stem cell therapy promotes the recovery of SCI mainly by replacing lost or damaged cells, providing nutritional support to neurons, protecting neurons, or improving the microenvironment in the spinal cord to allow the regeneration of damaged axons [2]. Mesenchymal stem cells (MSCs) are derived from various sources. Bone marrow, adipose tissue, umbilical cord blood, the placenta, and pulp contain large numbers of MSCs $[3,4]$. MSCs are the most commonly used stem cells in animal research and human clinical trials.

Exosomes are extracellular vesicles that can be released into the extracellular environment by all cells [5]. Exosomes can be easily isolated, are small in size, and can reach central nervous system (CNS) injuries by passing through the blood-brain barrier [6]. Therefore, they have a unique ability to treat diseases.

There have been many reports on the application of MSCs for SCI treatment. Recent studies have shown that the ability of MSCs to treat and repair an injured spinal cord is mainly related to the paracrine secretion of exosomes by MSCs, rather than to MSC substitution and multidirectional differentiation. This article briefly reviews the pathological process of SCI and provides information related to MSCs and exosomes. This article also discusses recent studies on the use of MSC-derived exosomes (MSC-exosomes) for the treatment of SCI. We attempt to clarify the repair mechanism of MSC-exosomes in the treatment of SCI and propose exploring the potential application value of MSC-exosomes in the field of cell-free therapy.

\section{Spinal Cord Injury}

SCI is a complicated process involving various factors, and its pathophysiological mechanism has not been fully elucidated. SCI involves primary SCI and secondary injury. Primary SCI is directly caused by an external force and

\footnotetext{
${ }^{1}$ Department of Basic Medical Sciences, College of Veterinary Medicine, Weldon School of Biomedical Engineering, Purdue University, West Lafayette, Indiana, USA.

${ }^{2}$ Key Laboratory of Animal Disease and Human Health of Sichuan Province, College of Veterinary Medicine, Sichuan Agricultural University, Yaan, China.

${ }^{3}$ Department of Orthopedics, National Clinical Research Center for Geriatric Diseases, Xuanwu Hospital, Capital Medical University, Beijing, China.

*These authors contributed equally to this work.
} 
Table 1. Pathophysiological Characteristics of Spinal Cord Injury

\begin{tabular}{|c|c|c|c|c|}
\hline \multirow{2}{*}{\multicolumn{2}{|c|}{ Type of injury primary SCI }} & \multicolumn{3}{|c|}{ Secondary SCI } \\
\hline & & $\begin{array}{l}\text { Acute phase } \\
\qquad(<2 d)\end{array}$ & $\begin{array}{l}\text { Intermediate } \\
\text { phase }(<14 d)\end{array}$ & $\begin{array}{l}\text { Chronic phase } \\
\text { (weeks/months) }\end{array}$ \\
\hline $\begin{array}{l}\text { Main } \\
\text { pathophysiological } \\
\text { events }\end{array}$ & $\begin{array}{l}\text { Axonal rupture of spinal cord } \\
\text { neurons } \\
\text { Destruction of blood vessels } \\
\text { and cell membranes }\end{array}$ & $\begin{array}{l}\text { Edema } \\
\text { Gray matter } \\
\quad \text { hemorrhage } \\
\text { BSCB disruption } \\
\text { Inflammation } \\
\text { Neuronal death } \\
\text { Demyelination }\end{array}$ & $\begin{array}{l}\text { Astrocyte activation } \\
\text { CSPGs deposition } \\
\text { Glial scar formation }\end{array}$ & $\begin{array}{l}\text { Waller's degeneration } \\
\text { Glial scar maturation } \\
\text { Cysts and syringomyelia }\end{array}$ \\
\hline References & [8] & & [18-20] & [21] \\
\hline
\end{tabular}

SCI, spinal cord injury; BSCB, blood-spinal cord barrier; CSPGs, chondroitin sulfate proteoglycans.

occurs within a few minutes after injury, whereas secondary injury is induced by a cascade of factors for several weeks after injury [7].

Injury to the spinal cord caused by an external mechanical force is called primary injury. Primary SCI can lead to spinal cord laceration, contusion, compression, or concussion. It eventually causes the axonal rupture of spinal cord neurons and the destruction of blood vessels and cell membranes [8].

The pathophysiological changes related to secondary SCI are the result of many complicated mechanisms. Secondary SCI can be divided into acute, intermediate, and chronic stages according to the time after injury and the pathological mechanism (Table 1).

Although SCI can be alleviated through self-repair mechanisms, recovery from SCI requires external intervention. Limiting secondary SCI, promoting axon and myelin for- mation, and reconstructing neural circuits are the keys in treating SCI [9]. Early surgical decompression and drug treatment for inhibition or alleviation of secondary injury, combined with daily rehabilitation training and nursing to restore functions, are the main treatments for SCI $[10,11]$.

\section{Mesenchymal Stem Cells}

Because MSCs are easier to obtain [22], they can be more easily isolated [23], have lower immunogenicity [24], and are subject to fewer ethical restrictions compared with other types of stem cells [25]; they are currently the focus of much research. Interest in MSCs mainly stems from their homing, proliferation, differentiation, secretion, and immunomodulatory abilities. However, because there are also some challenges associated with the application of MSCs, their feasibility and safety are unclear (Table 2).

Table 2. Characteristics and Functions of Mesenchymal Stem Cells

\begin{tabular}{|c|c|c|c|}
\hline & $\begin{array}{c}\text { The characteristics } \\
\text { of MSCs }\end{array}$ & Effects & References \\
\hline \multirow[t]{4}{*}{ Advantages } & $\begin{array}{l}\text { Homing } \\
\text { characteristics }\end{array}$ & $\begin{array}{l}\text { High efficiency of MSC therapy is related to the expression of the } \\
\text { CXCR } 4 \text { and CXCR7 genes } \\
\text { Upregulate the expression of the PI3K/AKT, Janus kinase (JAK)/ } \\
\text { STAT and mitogen-activated protein kinase (MAPK) genes }\end{array}$ & [26-29] \\
\hline & $\begin{array}{l}\text { Proliferation and } \\
\text { differentiation } \\
\text { ability }\end{array}$ & $\begin{array}{l}\text { Differentiate into neural stem cells } \\
\text { Differentiate into cells with phenotypic characteristics of } \\
\text { oligodendrocyte precursor cells } \\
\text { Differentiate into endothelial cells }\end{array}$ & [30-32] \\
\hline & Secretion capacity & $\begin{array}{l}\text { Secrete soluble factors and extracellular vesicles that play } \\
\text { anti-inflammatory, angiogenic, antiapoptotic and } \\
\text { immunomodulatory roles }\end{array}$ & {$[33,34]$} \\
\hline & $\begin{array}{l}\text { Immunomodulatory } \\
\text { characteristics }\end{array}$ & $\begin{array}{l}\text { Inhibit neutrophil apoptosis } \\
\text { Induce phenotypic transformation of macrophages } \\
\text { Inhibit recruitment and activation of NK cells } \\
\text { Inhibit DC cell maturation } \\
\text { Inhibit T cell proliferation } \\
\text { Maintain the balance between Tregs and Th17 cells } \\
\text { Inhibit B cell proliferation, differentiation, and immunoglobulin } \\
\text { secretion }\end{array}$ & {$[35-41]$} \\
\hline Disadvantages & & $\begin{array}{l}\text { Low survival rate of transplantation } \\
\text { Poor migration and homing abilities } \\
\text { Abnormal differentiation into adipocytes in glomeruli } \\
\text { Tumor tendency }\end{array}$ & {$[42-45]$} \\
\hline
\end{tabular}

CXCR, C-X-C motif chemokine receptor; JAK, Janus kinase; MAPK, mitogen-activated protein kinase; MSC, mesenchymal stem cell; STAT, signal transducer and activator of transcription. 


\section{MSC-Exosomes}

Extracellular vesicles can be divided into two categories, namely, ectosomes and exosomes [5]. Exosomes, which have a diameter of $\sim 40-160 \mathrm{~nm}$ [5], are vesicular bodies with a spherical lipid bilayer membrane [46] (Fig. 1). The biogenesis of exosomes involves a variety of pathways, including an endosomal sorting complex required for the transport (ESCRT)-dependent pathway and an ESCRT-independent pathway [47]. ESCRT comprises five different proteins [48]. ESCRT-0 recognizes ubiquitinated proteins, ESCRT-I/II/ III mediates the sprouting of intraluminal vesicles, and the Vps4 complex is responsible for final membrane scission and/or ESCRT recycling [47]. Recently, it was reported that apoptosis-linked gene 2-interacting protein X-ray (ALIX), as a protein related to multivesicle bodies biosynthesis, can directly recruit ESCRT-III to late endosomes independently of other ESCRT interactions, but the binding between ALIX and ESCRT-III requires the presence of lysobisphosphatidic acid [49]. After exosomes are released, the biological activities of the receptor cells are regulated by the release of cargo into the receptor cell through interactions between transmembrane proteins and the receptors on the target cell, endocytosis, or direct fusion of the exosome with the receptor cell membrane [50].

Exosomes contain a large number of complex molecules, such as proteins, lipids, and nucleic acids [51,52] (Fig. 2), which are related to the source cell [53]. Exosomes are rich in lipids that form lipid rafts [54]. The exosomes of different cell types have different lipid compositions [53]. There are also significant differences between exosome lipids in different areas of the same cell [55]. This indicates that even within the same cell, exosomes may be synthesized through different pathways. The proteins in exosomes are mainly involved in metabolism, energy pathways, cell growth, communication, and transportation [56]. The isolation and purification of exosomes affect the biological functions of exosome proteins [57]. Although the specific proteins and their levels expressed by exosomes from different cell types vary, some of these proteins are common surface markers and are widely used to identify exosomes [58]. In addition to carrying proteins and lipids, exosomes contain various nucleic acids, such as mRNA, miRNAs, and other noncoding RNAs (ncRNAs). Among these nucleic acids, miRNAs are rich in exosomes and have therefore received increasing attention. The content of miRNA in exosomes is different from that in the source cell

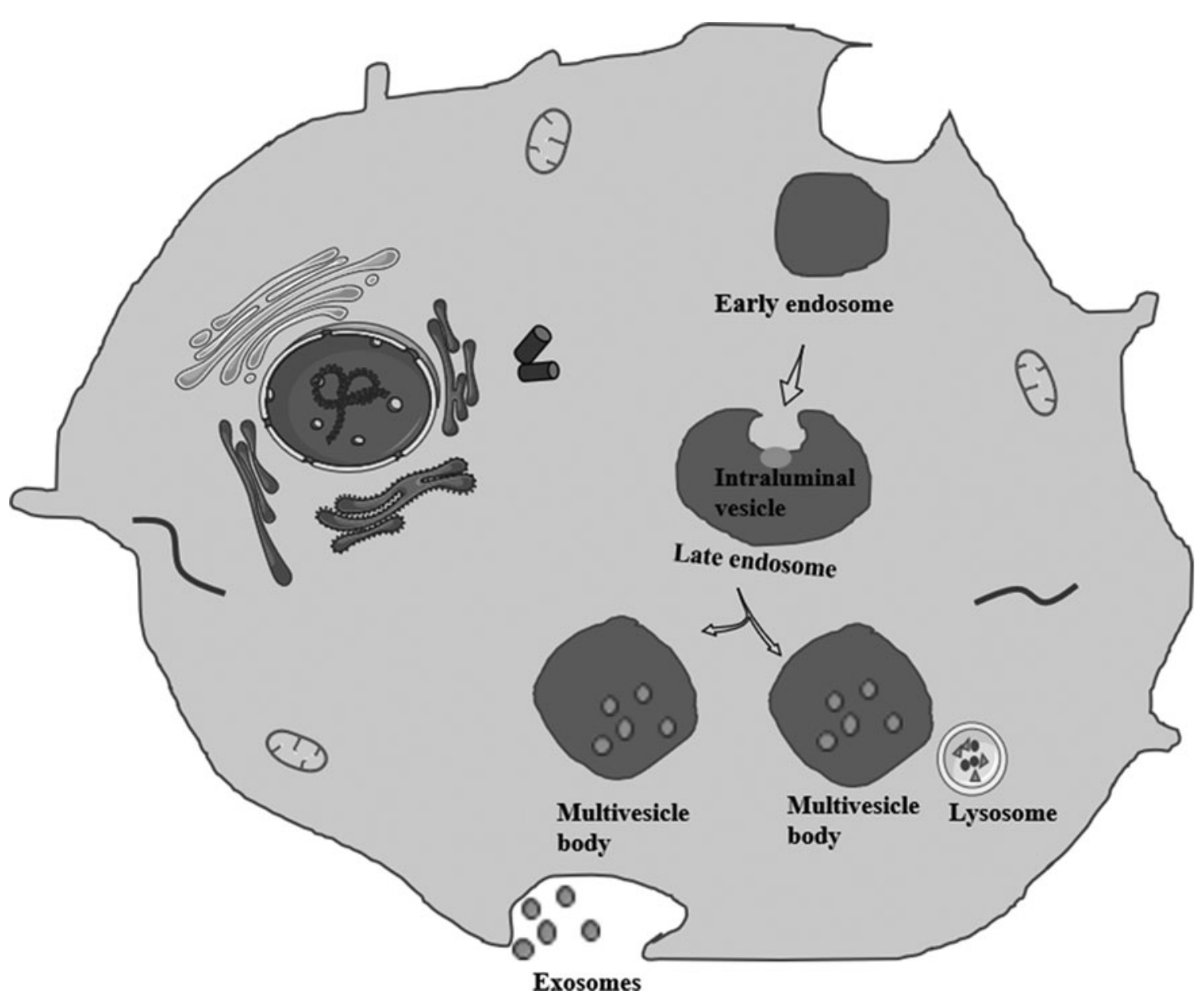

FIG. 1. Exosomes biogenesis: exosome biogenesis begins with the formation of early endosomes through cell membrane invagination. Early endosome bud inward, develop into late endosomes, and wrap specific cargos to form intraluminal vesicles. Late endosomes that contain several intraluminal vesicles transform into multivesicle bodies. Multivesicle bodies may be degraded by lysosomes or may fuse with the plasma membrane and be secreted into the extracellular environment as exosomes. 
FIG. 2. The molecular composition of exosomes: exosome lipids are derived from the cell membrane, and the lipid structure of the bilayer membrane protects the contents of the exosome. Exosomes contain a variety of proteins, including membrane proteins, such as tetraspanin family proteins (CD9, CD63, and CD81). Exosome proteins mainly include the MVB biosynthesis-related proteins apoptosis-linked gene 2-interacting protein X-ray (ALIX), tumor susceptibility gene 101 (TSG101) proteins, and heat shock proteins (HSP60, HSP70, and HSP90). In addition, exosomes also contain genetic materials such as DNA, miRNA, mRNA, and noncoding RNAs (ncRNAs).

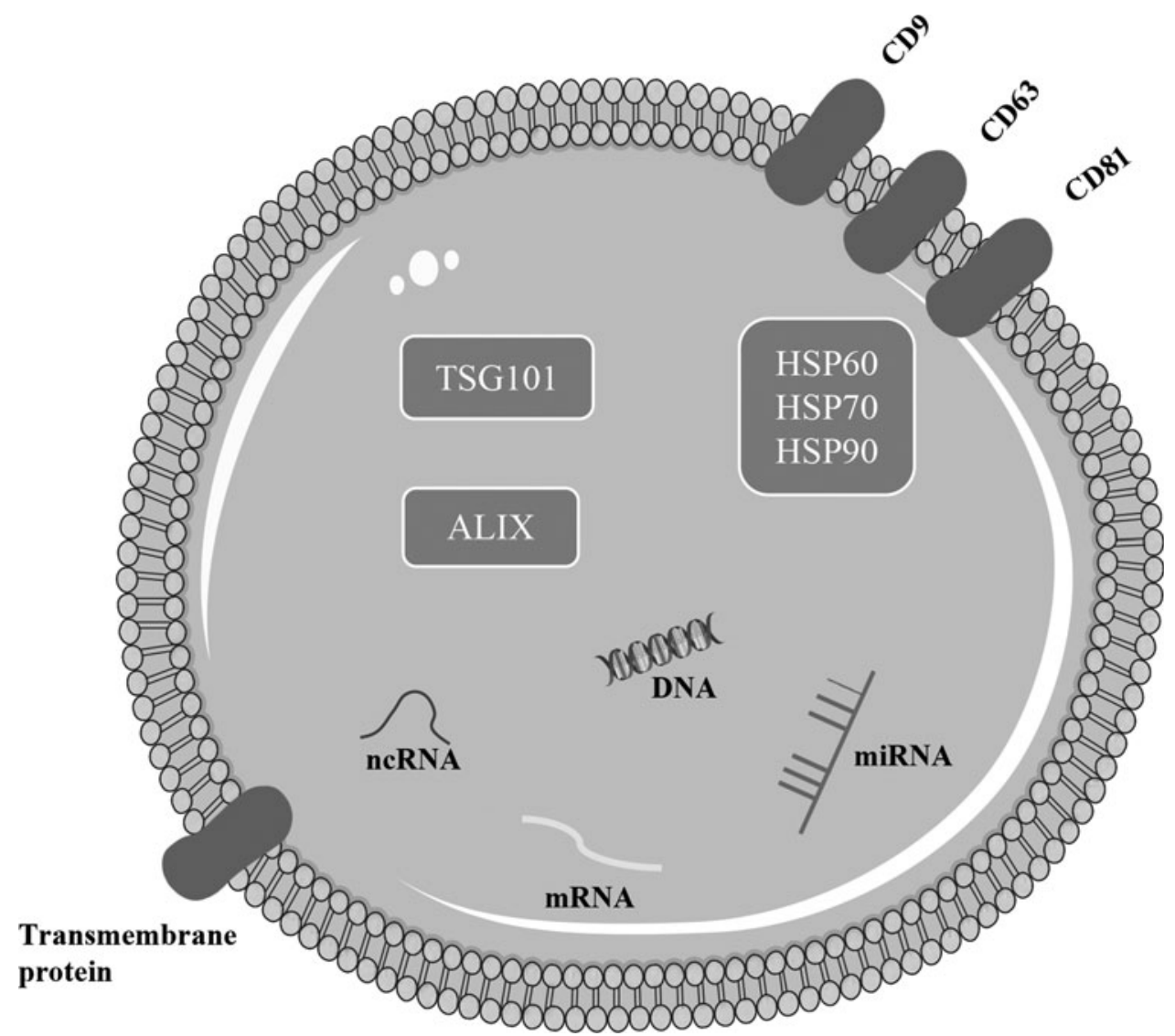

[59]. The content of miRNAs in exosomes during hypertension, cancer, nervous system diseases, and other diseases is significantly different from that in exosomes under physiological conditions [60-62]. Therefore, the miRNA content can be used as a marker for early diagnosis. In addition, exosomes can be used as efficient carriers to deliver specific miRNAs to receptor cells [63], allowing them to participate in a variety of physiological and pathological processes [64].

MSC-exosomes are mainly derived from bone marrow, adipose, and umbilical cord tissues. The cardiolipin content in MSC-exosomes is very high [53]. MSC-exosomes can also express iconic tetraspanin family members (CD9, CD63, and CD81), heat shock proteins (HSP) 70, and proteins associated with multivesicle bodies [ALIX and tumor susceptibility gene 101 (TSG101)] [65]. miRNAs in MSCexosomes are mainly involved in angiogenesis and tissue remodeling [66]. Among small RNAs, tRNAs are found at the highest levels in MSC-exosomes, and the types of tRNAs in MSC-exosomes from different sources vary [59]. The biological function of MSC-exosomes is similar to that of MSCs [67,68], but MSC-exosomes are more stable and do not induce tumorigenicity or immune rejection. MSCs produce more exosomes than cells from other sources [69]. Therefore, as alternatives to cell therapy, MSC-exosomes have great potential to promote recovery after injury.

\section{Effects of MSC-Exosomes on SCl: The Underlying Mechanisms}

At present, few clinical trials of MSC-exosomes in repair of SCI have been carried out, but there are many related preclinical studies being conducted (Table 3). Studies have shown that MSC-exosomes repair injured spinal cord tissue mainly by inducing angiogenesis and axon formation, regulating inflammation and the immune response, inhibiting apoptosis, and maintaining the integrity of the blood-spinal cord barrier (BSCB) (Fig. 3).

\section{MSC-exosomes promote angiogenesis}

Angiogenesis is crucial for SCI repair. Local blood vessel loss and blood-brain barrier disruption caused by injury can lead to ischemia and inflammation, which can cause comprehensive injury to spinal nerve tissue [89].

Vascular endothelial cells are important components of blood vessel walls. MSC-exosomes can upregulate the expression of key genes involved in angiogenesis in human umbilical vein endothelial cells (HUVECs). Vascular endothelial growth factor (VEGF) plays a key role in the MSCexosome-mediated proliferation and migration of HUVECs [90]. MSC-exosomes derived from induced pluripotent stem cells are directly taken up by HUVECs. There, they activate the expression of VEGF, angiogenin, and transforming growth factor-beta 1 (TGFB1) to promote the migration, proliferation, and tube formation of HUVECs [91]. After SCI, the spinal cord tissue is often in a hypoxic state. Hypoxia-treated MSC-exosomes are more easily taken up by HUVECs compared with normal MSC-exosomes and can also increase VEGF expression in HUVECs by activating the protein kinase A signaling pathway [92].

MSC-exosomes can release endogenous angiogenic miRNAs and transfer exogenous angiogenic miRNAs to 
Table 3. Current Preclinical Studies of Mesenchymal Stem Cell-Exosomes for Spinal Cord Injury Repair

\begin{tabular}{|c|c|c|c|c|c|c|}
\hline Year & $\begin{array}{l}\text { Source of } \\
\text { exosomes }\end{array}$ & $\begin{array}{l}\text { Exosome } \\
\text { isolation }\end{array}$ & $\begin{array}{l}\text { Animal model } \\
\text { of SCI }\end{array}$ & In vivo/in vitro effects & $\begin{array}{c}\text { Functional } \\
\text { cargo }\end{array}$ & References \\
\hline 2017 & $\begin{array}{l}\text { Bone } \\
\text { marrow }\end{array}$ & Centrifugation & Contusion (rat) & $\begin{array}{l}\text { Promote angiogenesis } \\
\text { Reduce apoptosis and } \\
\text { inflammation }\end{array}$ & / & {$[70]$} \\
\hline 2018 & $\begin{array}{l}\text { Bone } \\
\text { marrow }\end{array}$ & $\begin{array}{l}\text { Differential } \\
\text { centrifugation }\end{array}$ & Contusion (rat) & $\begin{array}{l}\text { Target M2 } \\
\text { macrophages }\end{array}$ & / & {$[71]$} \\
\hline 2018 & $\begin{array}{l}\text { Human } \\
\text { umbilical } \\
\text { cords }\end{array}$ & Centrifugation & Contusion (mice) & $\begin{array}{l}\text { Reduce inflammatory } \\
\text { response }\end{array}$ & / & [72] \\
\hline 2018 & $\begin{array}{l}\text { Bone } \\
\text { marrow }\end{array}$ & Centrifugation & Contusion (rat) & $\begin{array}{l}\text { Decrease the number of } \\
\text { A1 reactive } \\
\text { astrocytes }\end{array}$ & l & {$[18]$} \\
\hline 2018 & $\begin{array}{l}\text { Bone } \\
\text { marrow }\end{array}$ & $\begin{array}{l}\text { Differential } \\
\text { centrifugation }\end{array}$ & Contusion (rat) & $\begin{array}{l}\text { Reduce the proportion } \\
\text { of } A 1 \text { astrocytes }\end{array}$ & / & [73] \\
\hline 2018 & $\begin{array}{l}\text { Bone } \\
\text { marrow }\end{array}$ & Kit & $\begin{array}{l}\text { Clip compression } \\
\text { (rat) }\end{array}$ & $\begin{array}{l}\text { Protect neurons and } \\
\text { promote axonal } \\
\text { regeneration }\end{array}$ & $\operatorname{miR}-133 b$ & [74] \\
\hline 2019 & $\begin{array}{l}\text { Bone } \\
\text { marrow }\end{array}$ & Ultracentrifugation & Contusion (rat) & $\begin{array}{l}\text { Improve the integrity } \\
\text { of the BSCB }\end{array}$ & / & {$[75]$} \\
\hline 2019. & $\begin{array}{l}\text { Bone } \\
\text { marrow }\end{array}$ & Ultracentrifugation & $\begin{array}{l}\text { Complete spinal } \\
\text { cord transection } \\
\text { (rat) }\end{array}$ & Enhance axonal growth & PTEN siRNA & {$[76]$} \\
\hline 2019 & $\begin{array}{l}\text { Bone } \\
\text { marrow }\end{array}$ & Kit & $\begin{array}{l}\text { Hemisection } \\
\text { injury (rat) }\end{array}$ & $\begin{array}{l}\text { Inhibit complement } \\
\text { activation }\end{array}$ & / & {$[77]$} \\
\hline 2019 & Bone arrow & Ultracentrifugation & Contusion (rat) & Neuroprotection & / & {$[78]$} \\
\hline 2019 & $\begin{array}{l}\text { Bone } \\
\text { marrow }\end{array}$ & Ultracentrifugation & $\begin{array}{l}\text { Clip compression } \\
\text { (rat) }\end{array}$ & $\begin{array}{l}\text { Reduce injury area and } \\
\text { apoptosis }\end{array}$ & miR-21 & [79] \\
\hline 2019 & $\begin{array}{l}\text { Bone } \\
\text { marrow }\end{array}$ & Kit & Contusion (rat) & $\begin{array}{l}\text { Regulate neuronal } \\
\text { regeneration }\end{array}$ & $\operatorname{miR}-29 b$ & {$[80]$} \\
\hline 2019 & I & Kit & Contusion (rat) & $\begin{array}{l}\text { Suppress neuron } \\
\text { Cell death }\end{array}$ & miR-21 & [81] \\
\hline 2020 & $\begin{array}{l}\text { Bone } \\
\text { marrow }\end{array}$ & Ultracentrifugation & Contusion (rat) & $\begin{array}{l}\text { Promote neurogenesis } \\
\text { and reduce apoptosis }\end{array}$ & $\operatorname{miR}-126$ & {$[82]$} \\
\hline 2020 & $\begin{array}{l}\text { Bone } \\
\text { marrow }\end{array}$ & Ultracentrifugation & Contusion (mice) & $\begin{array}{l}\text { Mediate microglial } \\
\text { polarization }\end{array}$ & $\operatorname{miR}-216 a-5 p$ & [83] \\
\hline 2020 & $\begin{array}{l}\text { Bone } \\
\text { marrow }\end{array}$ & Ultracentrifugation & Compression (rat) & $\begin{array}{l}\text { Promote neuronal } \\
\text { survival }\end{array}$ & $\operatorname{miR}-544$ & [84] \\
\hline 2020 & $\begin{array}{l}\text { Bone } \\
\text { marrow }\end{array}$ & Ultracentrifugation & Weight drop (rat) & $\begin{array}{l}\text { Reduce glial scar } \\
\text { formation, } \\
\text { neuroinflammation, } \\
\text { and apoptosis }\end{array}$ & $\begin{array}{l}\text { G protein-coupled } \\
\text { receptor } \\
\text { kinase } 2 \\
\text { interacting } \\
\text { protein } 1\end{array}$ & {$[85]$} \\
\hline 2020 & $\begin{array}{l}\text { Bone } \\
\text { marrow }\end{array}$ & Ultracentrifugation & Weight drop (rat) & Activate autophagy & / 1 & {$[86]$} \\
\hline 2020 & $\begin{array}{l}\text { Bone } \\
\text { marrow }\end{array}$ & Kit & $\begin{array}{l}\text { Ischemia/ } \\
\text { reperfusion (rat) }\end{array}$ & $\begin{array}{l}\text { Induce M2 polarization } \\
\text { of macrophages }\end{array}$ & $\operatorname{miR}-124-3 p$ & {$[87]$} \\
\hline 2020 & $\begin{array}{l}\text { Human } \\
\text { placenta } \\
\text { amniotic } \\
\text { membrane }\end{array}$ & $\begin{array}{l}\text { Size-exclusion } \\
\text { chromatography and } \\
\text { ultracentrifugation }\end{array}$ & Transection (rat) & $\begin{array}{l}\text { Promote nerve tissue } \\
\text { Repair and functional } \\
\text { restoration }\end{array}$ & l & {$[88]$} \\
\hline
\end{tabular}

BSCB, blood-spinal cord barrier; PTEN, phosphatase and tensin homolog.

HUVECs to regulate the target gene of the miRNA. Human adipose-derived MSC-exosomes are rich in miR-125a. miR125a taken up by HUVECs inhibits the expression of deltalike ligand 4 and promotes angiogenesis by specifically binding to the $3^{\prime}$ untranslated region of delta-like ligand 4 [93]. miR-126-modified MSC-exosomes can also exert a similar proangiogenic effect, mainly by inhibiting the ability of miR-126 to directly target phosphoinositide-3-kinase regulatory subunit 2 and sprouty-related EVH1 domaincontaining protein 1 in HUVECs [82].

\section{MSC-exosomes promote axonal growth}

The regeneration of injured axons or the stimulation of the growth of spare axons at the injury site is of great significance for the recovery of spinal cord function after SCI [94].

MSC-exosomes can alleviate nerve conduction disorders by inducing axonal growth and reducing the production of chondroitin sulfate proteoglycans (CSPGs). MSC-exosomes can promote the axonal growth of cortical neurons in vitro. 


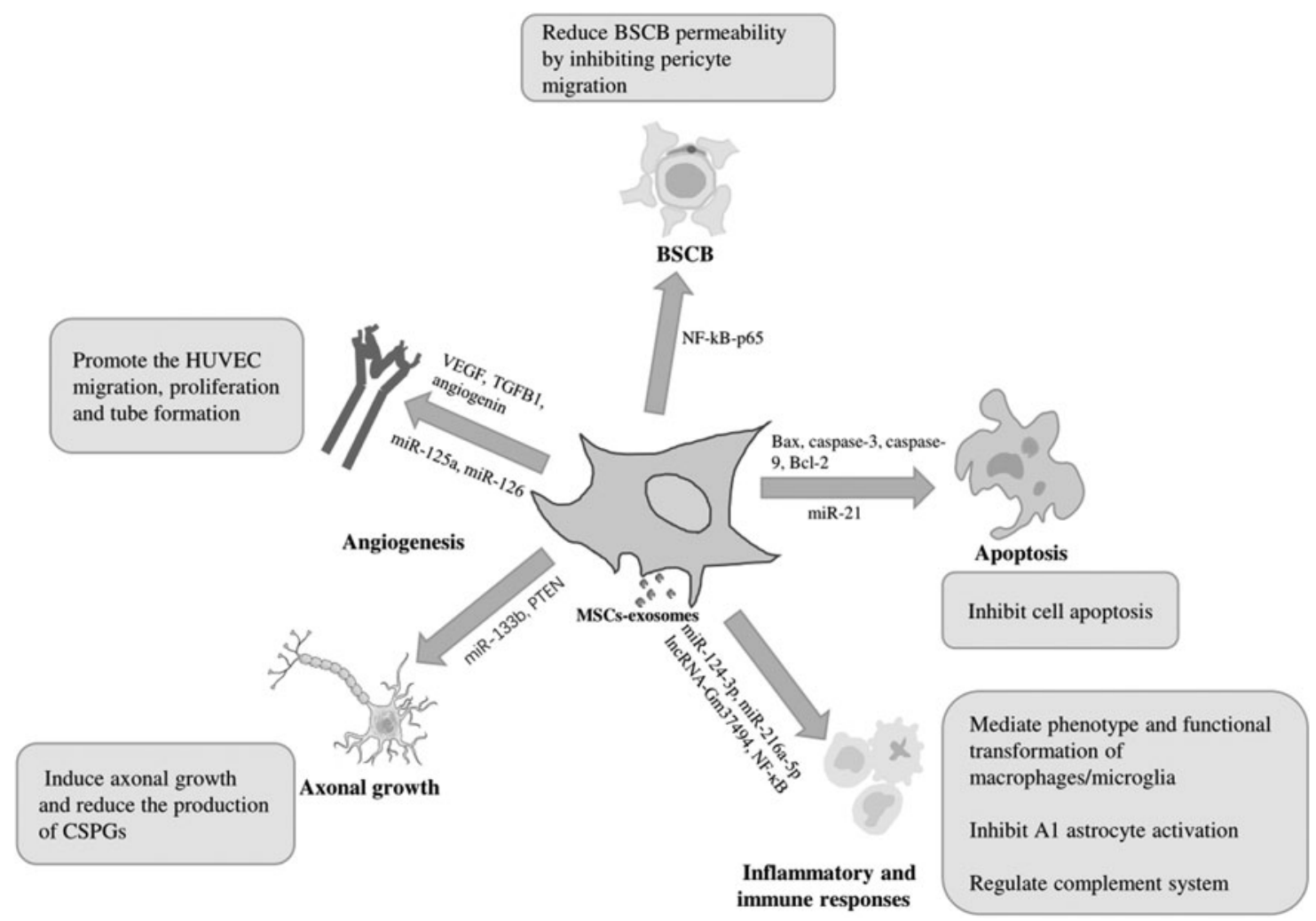

FIG. 3. Effects and mechanisms of MSC-exosomes on SCI. BSCB, blood-spinal cord barrier; CSPGs, chondroitin sulfate proteoglycans; HUVEC, human umbilical vein endothelial cells; lncRNA, long noncoding RNA; MSC-exosomes, mesenchymal stem cell-derived exosomes, NF- $\mathrm{B}$, nuclear factor kappa B; PTEN, phosphatase and tensin homolog; SCI, spinal cord injury; TGFB1, transforming growth factor-beta-1; VEGF, vascular endothelial growth factor.

The distal axon length increases by $33 \%$ and $24 \%$, respectively, in cortical neurons cultured with MSC-exosomes for 24 and $48 \mathrm{~h}$ compared with control neurons [95]. However, the internalization of MSC-exosomes into neurons and distal axons requires the core protein-soluble NSF attachment protein receptor, which mediates vesicle fusion at synapses [95]. Whether glial scarring hinders axonal regeneration is controversial. Recently, it was suggested that preventing or ablating astrocyte reactivity in the scar does not stimulate axonal growth or inhibit axonal regeneration. The main mechanism by which axonal regeneration is inhibited is the generation of CSPGs [96]. In rats subjected to spinal cord contusion and injected with MSC-exosomes, CSPG deposition in the spinal cord lesion area is significantly lower, and axonal regeneration is nearly $80 \%$ higher than that in untreated injured rats [18].

In addition, MSC-exosomes carrying specific miRNAs that mediate axonal growth can better promote axonal growth compared with MSC-exosomes carrying an empty vector. In a rat model of SCI, the injection of miR-133bmodified MSC-exosomes increases the expression of growthrelated protein 43 and neurofilament, indicating axonal regeneration [74]. miR-133b increases the expression of extracellular-regulated protein kinases $1 / 2$, signal transducer and signal transducer and activator of transcription (STAT) 3 , and cAMP-response element binding protein, to affect axon regeneration-related pathways [74]. By downregulating the high expression of phosphatase and tensin homolog (PTEN) after SCI, the intranasal delivery of PTEN gene- silenced MSC-exosomes can target damaged sites to promote axonal regeneration [76]. The PTEN-mammalian target of rapamycin (mTOR) pathway is a key factor in axonal regeneration [97]. The inhibition of PTEN can activate the synthesis of proteins downstream of mTOR signaling and promote the regeneration of injured CNS axons [98]. Therefore, MSC-exosomes can be used as efficient miRNA and small interfering RNA carriers for CNS diseases.

\section{MSC-exosomes regulate inflammatory and immune responses in $\mathrm{SCl}$}

MSC-derived exosomes can communicate with the inflammatory microenvironment to play a neuroprotective role and can adjust the complementary systems to promote spinal cord function recovery.

MSC-exosomes mediate the phenotype and functional transformation of macrophages/microglia. Microglia are macrophages in the CNS. Activated microglia and macrophages are also called macrophages/microglia because they are not easily distinguished [99]. Macrophages/microglia have high plasticity. Different subpopulations of macrophages/ microglia, namely, M1 proinflammatory macrophages and M2 anti-inflammatory macrophages, are present at the site of SCI [100]. The ratio of these two phenotypes is important for SCI repair.

MSC-exosomes can be specifically localized to the site of SCI in rats and can bind to M2 macrophages [71], thereby increasing the production of anti-inflammatory cytokines. 
In a mouse model of SCI, a tail vein injection of MSCexosomes can trigger the transformation of macrophages from the M1 phenotype to the M2 phenotype [72]. Activated M2 macrophages downregulate the release of tumor necrosis factor (TNF)- $\alpha$, macrophage inflammatory protein- $1 \alpha$, interleukin (IL)-6 and interferon (IFN)- $\gamma$ to reduce inflammation in the injured area and increase the expression of IL-4 and IL-10 to promote healing of the injury site [72]. However, the mechanism through which MSC-exosomes mediate the phenotypic transformation of macrophages was proven to require stimulation by proinflammatory factors. After preactivation of the proinflammatory cytokines IFN- $\gamma$ / TNF- $\alpha$, MSC exosomes acquire the ability to shift M1 macrophages to the M2 phenotype. This process may be related to miRNAs in MSC-exosomes, such as miR-34a-5p, miR-21, and miR146a-5p [101].

MSC-exosomes can regulate macrophage/microglial polarization through regulation of pathways by exogenous miRNAs and long ncRNAs (lncRNAs). Endoplasmic reticulum stress is induced after SCI [102], and miR-124-3p can inhibit the expression of the endoplasmic reticulum to nucleus signaling 1 , which is a major regulator of endoplasmic reticulum stress [87]. Exogenous miR-124-3p is transferred to macrophages through MSC-exosomes and enhances the polarization of M2 macrophages by inhibiting the expression of endoplasmic reticulum to nucleus signaling 1 [87]. In addition, MSC-exosomes carrying miR-216a-5p activate phosphatidylinositide 3-kinases (PI3K)/serine/threonine kinase $(\mathrm{AKT})$, inhibit the Toll-like receptor 4/nuclear factor kappa B (NF- $\mathrm{B})$ signaling pathways, and transform M1 microglia into M2 microglia [83]. MSC-exosomes can also carry lncRNAs with nerve repair functions to target cells. MSC-exosomes modified by lncRNA-Gm37494 can shift the M1/M2 phenotype of microglia/macrophage M1/M2 phenotypes by inhibiting miR-130b-3p and promoting the expression of peroxisome proliferator-activated receptor $\gamma$ [103].

MSC-exosomes inhibit Al astrocyte activation. Neuroinflammation and ischemia in the CNS can alter the phenotypes of A1 and A2 reactive astrocytes, respectively [104]. A1 astrocytes, which are induced by IL- $1 \alpha, \mathrm{TNF}-\alpha$, and C1q secreted by microglia, lose the ability to promote neuronal survival, synapse formation, growth, and phagocytosis and can also lead to neuronal and oligodendrocyte death [105]. However, A2 astrocytes promote neuronal survival and tissue repair [104].

MSC-exosomes can exert anti-inflammatory and neuroprotective effects by inhibiting the activation of NF-кBp65, thereby reducing the number of A1reactive astrocytes. MSC-exosomes can reduce the expression of the A1 astrocyte marker glial fibrillary acidic protein and its complement $\mathrm{C} 3$ in astrocytes [73]. They can also reduce the expression of the NF- $\kappa \mathrm{B}$-related protein $\mathrm{p}-\mathrm{IkB} \alpha$ and nuclear p-p65, but the expression of NF- $\kappa \mathrm{B}$ inhibits protein IkB- $\alpha$ from regulating the $\mathrm{NF}-\kappa \mathrm{B}$ signaling pathway [73].

$M S C$-exosomes regulate the complement system. Both classic and alternative complement pathways can be activated after SCI [106]. The activation of these pathways may aggravate the inflammatory process and secondary injury to the spinal cord.

MSC-exosomes can be used as complementary inhibitors to reduce complementary mRNA expression while inhibiting the $\mathrm{NF}-\kappa \mathrm{B}$ signaling pathway and promoting SCI recovery. In SCI rats injected with MSC-exosomes, the mRNA levels of complements $\mathrm{C} 1 \mathrm{q}$, complement factor $\mathrm{H}$, C3, C4b, C6, C5, mannan-binding lectin, and complement factor $\mathrm{P}$ are lower than those in uninjected SCI rats, and SCI is alleviated [77]. Complements $\mathrm{C} 1 \mathrm{q}$ and $\mathrm{C} 3$ are related to the NF- $\kappa \mathrm{B}$ signaling pathway $[107,108]$. The secondary inflammatory response caused by SCI is regulated by NF- $\kappa \mathrm{B}$ [109]. Inhibiting $\mathrm{NF}-\kappa \mathrm{B}$ can reduce the inflammatory response and promote functional recovery after SCI. In addition, MSC-exosomes can downregulate $\mathrm{p}-\mathrm{NF}-\kappa \mathrm{B}$ and phosphorylated-I $\kappa \mathrm{B} \alpha$ levels and inhibit SCI-induced NF- $\kappa \mathrm{B}$ subunit expression [77]. Therefore, targeting key complements with MSC-exosomes may be an effective method for alleviating SCI.

\section{MSC-exosomes inhibit cell apoptosis}

Apoptosis in secondary SCI leads to irreversible changes in neurons and aggravates damage. Therefore, it is necessary to suppress neuronal apoptosis.

MSC-exosomes reduce apoptosis by regulating apoptosisrelated proteins and miRNA transfer. MSC-exosomes can significantly downregulate the apoptosis-related markers Bax, caspase-3, and caspase-9 in rats after SCI, increase the level of the antiapoptotic protein Bcl-2 and further enhance the $\mathrm{Wnt} / \beta$-catenin signaling pathway to exert an antiapoptotic effect [78]. In addition, MSC-exosomes can also reduce neuronal apoptosis by promoting neuronal autophagy. MSC-exosomes can activate autophagy and increase the number of autophagosomes [86]. Consistent with in vitro findings, MSC-exosomes increase the expression of the autophagy-related proteins Beclin-1 and LC3-II in SCI rats on the third day after treatment but decrease the protein expression of P62 [86].

As one of the miRNAs that is significantly upregulated after SCI, miR-21 can downregulate the expression of PTEN, programmed cell death factor 4 (PDCD4), and FasL. It also inhibits neuronal apoptosis and plays a protective role. MSC-exosomes transfected with miR-21 can inhibit the expression of PTEN/PDCD4 and reduce nerve cell apoptosis [81]. In addition, miR-21-5p exerts an antiapoptotic effect that is also related to the decreased expression of FasL, which is a proapoptotic gene [110]. Of note, miR-21 deficiency in obese rats is caused by insulin resistance, and secreted MSC-exosomes have no significant effect on SCI rats [79]. The above results further prove that MSC-derived exosomes can alleviate SCI by inhibiting apoptosis. The functions of MSC-exosomes carrying specific miRNAs that inhibit apoptosis are affected under certain pathophysiological conditions.

\section{MSC-exosomes reduce the BSCB permeability by inhibiting pericyte migration}

Pericytes are indispensable for the formation and function of the BSCB. The loss of barrier integrity leads to increased permeability and the penetration of toxic products into the spinal cord, resulting in edema and death of spinal cord neurons [111].

MSC-exosomes injected into the injury site of contusion SCI rats are taken up by pericytes and downregulate NF$\kappa$ Bp65 in these cells to inhibit pericyte migration, improve 
the coverage of pericytes, and reduce the permeability of the BSCB [75]. Previous studies have explored how MSCexosomes maintain the integrity of the BSCB after SCI. Thus, targeting the BSCB is a promising treatment strategy for SCI.

\section{Conclusions}

Taken together, these data suggest that MSC-exosomes are new tools for SCI repair. However, before they can be used for clinical applications, the many challenges related to the tissue sources, isolation, purification, amplification, and joint application of MSC-exosomes need to be addressed.

MSC-exosomes from various tissue sources contain different inclusions and thus have distinct abilities to repair damage. In practical applications, MSC-exosomes should be chosen according to the functions of different source tissues. The physical and chemical properties of MSC-exosomes obtained through different separation methods are also different. It is necessary to establish a quick, cheap, and simple standardized separation and purification procedure to generate MSC-exosomes with a high yield and purity without impacting the biological activity of the exosomes. Obtaining a sufficient number of MSC-exosomes for repair is also a challenge. Physiological stimuli or small-molecule modulator pretreatment can increase the secretion of MSCexosomes [112]. However, the physical and chemical properties, composition, and function of MSC-exosomes obtained using these methods need to be investigated in depth. Because of the limitations related to the application of MSC-exosomes alone, many studies currently use MSCexosomes in combination with biological materials or use MSC-exosomes as gene or drug delivery vehicles. Thus, the combined effects of MSC-exosomes and the mechanism of targeted delivery need to be further elucidated.

In conclusion, we believe that the combination of MSCexosomes and SCI has infinite potential. Research on the detailed mechanism and further evaluation of the safety and effectiveness of MSC-exosomes and SCI will promote the development of this field.

\section{Acknowledgment}

The authors thank American Journal Experts, LLC, for editing the English text of a draft of this article.

\section{Author Disclosure Statement}

The authors declare that they have no conflicts of interest.

\section{Funding Information}

This study was supported by the Visiting Scholar Program sponsored by the China Scholarship Council (201906915019), the National Natural Science Foundation of China (no. 81871794), and the Beijing Municipal Health Commission (Jing2019-2).

\section{References}

1. Shao A, S Tu, J Lu and J Zhang. (2019). Crosstalk between stem cell and spinal cord injury: pathophysiology and treatment strategies. Stem Cell Res Ther 10:238.
2. Sahni V and JA Kessler. (2010). Stem cell therapies for spinal cord injury. Nat Rev Neurol 6:363-372.

3. Yamada Y, S Nakamura-Yamada, K Kusano and S Baba. (2019). Clinical potential and current progress of dental pulp stem cells for various systemic diseases in regenerative medicine: a concise review. Int J Mol Sci 20:1132.

4. Heo JS, Y Choi, HS Kim and HO Kim. (2016). Comparison of molecular profiles of human mesenchymal stem cells derived from bone marrow, umbilical cord blood, placenta and adipose tissue. Int J Mol Med 37:115125.

5. Kalluri R and VS LeBleu. (2020). The biology, function, and biomedical applications of exosomes. Science 367: eaau6977.

6. Luarte A, LF Batiz, U Wyneken and C Lafourcade. (2016). Potential therapies by stem cell-derived exosomes in CNS diseases: focusing on the neurogenic niche. Stem Cells Int 2016:5736059.

7. Nas K, L Yazmalar, V Sah, A Aydin and K Ones. (2015). Rehabilitation of spinal cord injuries. World J Orthop 6: 8-16.

8. Rowland JW, GW Hawryluk, B Kwon and MG Fehlings. (2008). Current status of acute spinal cord injury pathophysiology and emerging therapies: promise on the horizon. Neurosurg Focus 25:E2.

9. Tran AP, PM Warren and J Silver. (2018). The biology of regeneration failure and success after spinal cord injury. Physiol Rev 98:881-917.

10. Karsy M and G Hawryluk. (2019). Modern medical management of spinal cord injury. Curr Neurol Neurosci Rep 19:65.

11. Bailey J, MP Dijkers, J Gassaway, J Thomas, P Lingefelt, SE Kreider and G Whiteneck. (2012). Relationship of nursing education and care management inpatient rehabilitation interventions and patient characteristics to outcomes following spinal cord injury: the SCIRehab project. J Spinal Cord Med 35:593-610.

12. Leypold BG, AE Flanders and AS Burns. (2008). The early evolution of spinal cord lesions on MR imaging following traumatic spinal cord injury. AJNR Am J Neuroradiol 29:1012-1016.

13. Losey P, C Young, E Krimholtz, R Bordet and DC Anthony. (2014). The role of hemorrhage following spinal-cord injury. Brain Res 1569:9-18.

14. Kumar H, AE Ropper, SH Lee and I Han. (2017). Propitious therapeutic modulators to prevent blood-spinal cord barrier disruption in spinal cord injury. Mol Neurobiol 54:3578-3590.

15. Yu Q, J Huang, J Hu and H Zhu. (2016). Advance in spinal cord ischemia reperfusion injury: blood-spinal cord barrier and remote ischemic preconditioning. Life Sci 154: 34-38.

16. Kim YH, KY Ha and SI Kim. (2017). Spinal cord injury and related clinical trials. Clin Orthop Surg 9:1-9.

17. Anwar MA, TS Al Shehabi and AH Eid. (2016). Inflammogenesis of secondary spinal cord injury. Front Cell Neurosci 10:98.

18. Liu W, Y Wang, F Gong, Y Rong, Y Luo, P Tang, Z Zhou, Z Zhou, T Xu, et al. (2019). Exosomes derived from bone mesenchymal stem cells repair traumatic spinal cord injury by suppressing the activation of A1 neurotoxic reactive astrocytes. J Neurotrauma 36:469-484.

19. Faulkner JR, JE Herrmann, MJ Woo, KE Tansey, NB Doan and MV Sofroniew. (2004). Reactive astrocytes 
protect tissue and preserve function after spinal cord injury. J Neurosci 24:2143-2155.

20. Okada S, M Hara, K Kobayakawa, Y Matsumoto and Y Nakashima. (2018). Astrocyte reactivity and astrogliosis after spinal cord injury. Neurosci Res 126:39-43.

21. Silva NA, N Sousa, RL Reis and AJ Salgado. (2014). From basics to clinical: a comprehensive review on spinal cord injury. Prog Neurobiol 114:25-57.

22. Stewart MC and AA Stewart. (2011). Mesenchymal stem cells: characteristics, sources, and mechanisms of action. Vet Clin North Am Equine Pract 27:243-261.

23. Zhang W, F Zhang, H Shi, R Tan, S Han, G Ye, S Pan, F Sun and X Liu. (2014). Comparisons of rabbit bone marrow mesenchymal stem cell isolation and culture methods in vitro. PLoS One 9:e88794.

24. Groh ME, B Maitra, E Szekely and ON Koc. (2005). Human mesenchymal stem cells require monocytemediated activation to suppress alloreactive T cells. Exp Hematol 33:928-934.

25. Volarevic V, BS Markovic, M Gazdic, A Volarevic, N Jovicic, N Arsenijevic, L Armstrong, V Djonov, M Lako and M Stojkovic. (2018). Ethical and safety issues of stem cell-based therapy. Int J Med Sci 15:36-45.

26. De Becker A and IV Riet. (2016). Homing and migration of mesenchymal stromal cells: how to improve the efficacy of cell therapy? World J Stem Cells 8:73-87.

27. Yang JX, N Zhang, HW Wang, P Gao, QP Yang and QP Wen. (2015). CXCR4 receptor overexpression in mesenchymal stem cells facilitates treatment of acute lung injury in rats. J Biol Chem 290:1994-2006.

28. Shao Y, F Zhou, D He, L Zhang and J Shen. (2019). Overexpression of CXCR7 promotes mesenchymal stem cells to repair phosgene-induced acute lung injury in rats. Biomed Pharmacother 109:1233-1239.

29. Popielarczyk TL, WR Huckle and JG Barrett. (2019). Human bone marrow-derived mesenchymal stem cells home via the PI3K-Akt, MAPK, and Jak/Stat signaling pathways in response to platelet-derived growth factor. Stem Cells Dev 28:1191-1202.

30. Chen S, W Zhang, JM Wang, HT Duan, JH Kong, YX Wang, M Dong, X Bi and J Song. (2016). Differentiation of isolated human umbilical cord mesenchymal stem cells into neural stem cells. Int J Ophthalmol 9:41-47.

31. Leite C, NT Silva, S Mendes, A Ribeiro, JP de Faria, T Lourenco, F dos Santos, PZ Andrade, CM Cardoso, et al. (2014). Differentiation of human umbilical cord matrix mesenchymal stem cells into neural-like progenitor cells and maturation into an oligodendroglial-like lineage. PLoS One 9:e111059.

32. Wang C, Y Li, M Yang, Y Zou, H Liu, Z Liang, Y Yin, G Niu, Z Yan and B Zhang. (2018). Efficient differentiation of bone marrow mesenchymal stem cells into endothelial cells in vitro. Eur J Vasc Endovasc Surg 55: 257-265.

33. Konala VB, MK Mamidi, R Bhonde, AK Das, R Pochampally and R Pal. (2016). The current landscape of the mesenchymal stromal cell secretome: a new paradigm for cell-free regeneration. Cytotherapy 18:13-24.

34. Sobacchi C, E Palagano, A Villa and C Menale. (2017). Soluble factors on stage to direct mesenchymal stem cells fate. Front Bioeng Biotechnol 5:32.

35. Salami F, A Tavassoli, J Mehrzad and A Parham. (2018). Immunomodulatory effects of mesenchymal stem cells on leukocytes with emphasis on neutrophils. Immunobiology 223:786-791.

36. Abumaree MH, MA Al Jumah, B Kalionis, D Jawdat, A Al Khaldi, FM Abomaray, AS Fatani, LW Chamley and BA Knawy. (2013). Human placental mesenchymal stem cells (pMSCs) play a role as immune suppressive cells by shifting macrophage differentiation from inflammatory M1 to anti-inflammatory M2 macrophages. Stem Cell Rev Rep 9:620-641.

37. Qu M, J Cui, J Zhu, Y Ma, X Yuan, J Shi, D Guo and C Li. (2015). Bone marrow-derived mesenchymal stem cells suppress NK cell recruitment and activation in PolyI: C-induced liver injury. Biochem Biophys Res Commun 466:173-179.

38. Zhu H, F Yang, B Tang, XM Li, YN Chu, YL Liu, SG Wang, DC Wu and Y Zhang. (2015). Mesenchymal stem cells attenuated PLGA-induced inflammatory responses by inhibiting host DC maturation and function. Biomaterials 53:688-698.

39. Sandrasaigaran P, SJR Algraittee, AR Ahmad, S Vidyadaran and R Ramasamy. (2018). Characterisation and immunosuppressive activity of human cartilage-derived mesenchymal stem cells. Cytotechnology 70:10371050.

40. Wang L, M Shi, L Tong, J Wang, S Ji, J Bi, C Chen, J Jiang, C Bai, J Zhou and Y Song. (2019). Lung-resident mesenchymal stem cells promote repair of LPS-induced acute lung injury via regulating the balance of regulatory $\mathrm{T}$ cells and Th17 cells. Inflammation 42:199-210.

41. Che N, X Li, S Zhou, R Liu, D Shi, L Lu and L Sun. (2012). Umbilical cord mesenchymal stem cells suppress B-cell proliferation and differentiation. Cell Immunol 274: $46-53$.

42. Li L, X Chen, WE Wang and C Zeng. (2016). How to improve the survival of transplanted mesenchymal stem cell in ischemic heart? Stem Cells Int 2016:9682757.

43. Gheisari Y, Azadmanesh K, Ahmadbeigi N, Nassiri SM, Golestaneh AF, Naderi M, Vasei M, Arefian E, MirabSamiee S, et al. (2012). Genetic modification of mesenchymal stem cells to overexpress CXCR4 and CXCR7 does not improve the homing and therapeutic potentials of these cells in experimental acute kidney injury. Stem Cells Dev 21:2969-2980.

44. Kunter U, S Rong, P Boor, F Eitner, G Muller-Newen, Z Djuric, CR van Roeyen, A Konieczny, T Ostendorf, et al. (2007). Mesenchymal stem cells prevent progressive experimental renal failure but maldifferentiate into glomerular adipocytes. J Am Soc Nephrol 18:1754-1764.

45. Chen Y, Y He, X Wang, F Lu and J Gao. (2019). Adiposederived mesenchymal stem cells exhibit tumor tropism and promote tumorsphere formation of breast cancer cells. Oncol Rep 41:2126-2136.

46. Cocucci E and J Meldolesi. (2015). Ectosomes and exosomes: shedding the confusion between extracellular vesicles. Trends Cell Biol 25:364-372.

47. Juan T and M Furthauer. (2018). Biogenesis and function of ESCRT-dependent extracellular vesicles. Semin Cell Dev Biol 74:66-77.

48. Henne WM, NJ Buchkovich and SD Emr. (2011). The ESCRT pathway. Dev Cell 21:77-91.

49. Larios J, V Mercier, A Roux and J Gruenberg. (2020). ALIX-and ESCRT-III-dependent sorting of tetraspanins to exosomes. J Cell Biol 219:e201904113. 
50. Zhang J, S Li, L Li, M Li, C Guo, J Yao and S Mi. (2015). Exosome and exosomal microRNA: trafficking, sorting, and function. Genomics Proteomics Bioinformatics 13: $17-24$.

51. Colombo M, G Raposo and C Thery. (2014). Biogenesis, secretion, and intercellular interactions of exosomes and other extracellular vesicles. Annu Rev Cell Dev Biol 30: 255-289.

52. Rashed MH, E Bayraktar, KG Helal, MF Abd-Ellah, $\mathrm{P}$ Amero, A Chavez-Reyes and $\mathrm{C}$ Rodriguez-Aguayo. (2017). Exosomes: from garbage bins to promising therapeutic targets. Int J Mol Sci 18:538.

53. Haraszti RA, MC Didiot, E Sapp, J Leszyk, SA Shaffer, HE Rockwell, F Gao, NR Narain, M DiFiglia, et al (2016). High-resolution proteomic and lipidomic analysis of exosomes and microvesicles from different cell sources. J Extracell Vesicles 5:32570.

54. Elsherbini A and Bieberich E. (2018). Ceramide and exosomes: a novel target in cancer biology and therapy. Adv Cancer Res 140:121-154.

55. Dang VD, KK Jella, RRT Ragheb, ND Denslow and AA Alli. (2017). Lipidomic and proteomic analysis of exosomes from mouse cortical collecting duct cells FASEB J 31:5399-5408.

56. Yang C, WB Guo, WS Zhang, J Bian, JK Yang, QZ Zhou, MK Chen, W Peng, T Qi, CY Wang and CD Liu. (2017). Comprehensive proteomics analysis of exosomes derived from human seminal plasma. Andrology 5:1007-1015.

57. Burkova EE, AE Grigor'eva, DV Bulgakov, PS Dmitrenok, VV Vlassov, EI Ryabchikova, SE Sedykh and GA Nevinsky. (2019). Extra purified exosomes from human placenta contain an unpredictable small number of different major proteins. Int J Mol Sci 20:2434.

58. Yang XX, C Sun, L Wang and XL Guo. (2019). New insight into isolation, identification techniques and medical applications of exosomes. J Control Release 308:119129.

59. Baglio SR, K Rooijers, D Koppers-Lalic, FJ Verweij, M Perez Lanzon, N Zini, B Naaijkens, F Perut, HW Niessen, N Baldini and DM Pegtel. (2015). Human bone marrowand adipose-mesenchymal stem cells secrete exosomes enriched in distinctive miRNA and tRNA species. Stem Cell Res Ther 6:127.

60. Motawi TMK, D Sabry, NW Maurice and SM Rizk. (2018). Role of mesenchymal stem cells exosomes derived microRNAs; miR-136, miR-494 and miR-495 in pre-eclampsia diagnosis and evaluation. Arch Biochem Biophys 659:13-21.

61. Zhao L, J Yu, J Wang, H Li, J Che and B Cao. (2017). Isolation and Identification of miRNAs in exosomes derived from serum of colon cancer patients. J Cancer 8: $1145-1152$

62. Liu X, W Yuan, L Yang, J Li and J Cai. (2019). miRNA profiling of exosomes from spontaneous hypertensive rats using next-generation sequencing. J Cardiovasc Transl Res 12:75-83.

63. Zhang D, H Lee, Z Zhu, JK Minhas and Y Jin. (2017). Enrichment of selective miRNAs in exosomes and delivery of exosomal miRNAs in vitro and in vivo. Am $\mathrm{J}$ Physiol Lung Cell Mol Physiol 312:L110-L121.

64. Gho YS and C Lee. (2017). Emergent properties of extracellular vesicles: a holistic approach to decode the complexity of intercellular communication networks. Mol Biosyst 13:1291-1296.
65. Mendt M, K Rezvani and E Shpall. (2019). Mesenchymal stem cell-derived exosomes for clinical use. Bone Marrow Transplant 54:789-792.

66. Ferguson SW, J Wang, CJ Lee, M Liu, S Neelamegham, JM Canty and J Nguyen. (2018). The microRNA regulatory landscape of MSC-derived exosomes: a systems view. Sci Rep 8:1419.

67. Phinney DG and MF Pittenger. (2017). Concise review: MSC-derived exosomes for cell-free therapy. Stem Cells 35:851-858.

68. Mardpour S, AA Hamidieh, S Taleahmad, F Sharifzad, A Taghikhani and H Baharvand. (2019). Interaction between mesenchymal stromal cell-derived extracellular vesicles and immune cells by distinct protein content. J Cell Physiol 234:8249-8258.

69. Yeo RW, RC Lai, B Zhang, SS Tan, Y Yin, BJ Teh and SK Lim. (2013). Mesenchymal stem cell: an efficient mass producer of exosomes for drug delivery. Adv Drug Deliv Rev 65:336-341.

70. Huang JH, XM Yin, Y Xu, CC Xu, X Lin, FB Ye, Y Cao and FY Lin. (2017). Systemic administration of exosomes released from mesenchymal stromal cells attenuates apoptosis, inflammation, and promotes angiogenesis after spinal cord injury in rats. J Neurotrauma 34:33883396.

71. Lankford KL, EJ Arroyo, K Nazimek, K Bryniarski, PW Askenase and JD Kocsis. (2018). Intravenously delivered mesenchymal stem cell-derived exosomes target M2-type macrophages in the injured spinal cord. PLoS One 13:e0190358.

72. Sun G, G Li, D Li, W Huang, R Zhang, H Zhang, Y Duan and B Wang. (2018). hucMSC derived exosomes promote functional recovery in spinal cord injury mice via attenuating inflammation. Mater Sci Eng C Mater Biol Appl 89:194-204.

73. Wang L, S Pei, L Han, B Guo, Y Li, R Duan, Y Yao, B Xue, X Chen and Y Jia. (2018). Mesenchymal stem cell-derived exosomes reduce A1 astrocytes via downregulation of phosphorylated NFkappaB P65 subunit in spinal cord injury. Cell Physiol Biochem 50:15351559 .

74. Li D, P Zhang, X Yao, H Li, H Shen, X Li, J Wu and $X$ Lu. (2018). Exosomes derived from miR-133b-modified mesenchymal stem cells promote recovery after spinal cord injury. Front Neurosci 12:845.

75. Lu Y, Y Zhou, R Zhang, L Wen, K Wu, Y Li, Y Yao, R Duan and Y Jia. (2019). Bone mesenchymal stem cellderived extracellular vesicles promote recovery following spinal cord injury via improvement of the integrity of the blood-spinal cord barrier. Front Neurosci 13:209.

76. Guo S, N Perets, O Betzer, S Ben-Shaul, A Sheinin, I Michaelevski, R Popovtzer, D Offen and S Levenberg. (2019). Intranasal delivery of mesenchymal stem cell derived exosomes loaded with phosphatase and tensin homolog siRNA repairs complete spinal cord injury. ACS Nano 13:10015-10028.

77. Zhao C, X Zhou, J Qiu, D Xin, T Li, X Chu, H Yuan, H Wang, Z Wang and D Wang. (2019). Exosomes derived from bone marrow mesenchymal stem cells inhibit complement activation in rats with spinal cord injury. Drug Des Devel Ther 13:3693-3704.

78. Li C, G Jiao, W Wu, H Wang, S Ren, L Zhang, H Zhou, H Liu and Y Chen. (2019). Exosomes from bone marrow mesenchymal stem cells inhibit neuronal apoptosis and 
promote motor function recovery via the $\mathrm{Wnt} /$ beta-catenin signaling pathway. Cell Transplant 28:1373-1383.

79. Ji W, W Jiang, M Li, J Li and Z Li. (2019). miR-21 deficiency contributes to the impaired protective effects of obese rat mesenchymal stem cell-derived exosomes against spinal cord injury. Biochimie 167:171-178.

80. Yu T, C Zhao, S Hou, W Zhou, B Wang and Y Chen. (2019). Exosomes secreted from miRNA-29b-modified mesenchymal stem cells repaired spinal cord injury in rats. Braz J Med Biol Res 52:e8735.

81. Kang J, Z Li, Z Zhi, S Wang and G Xu. (2019). MiR-21 derived from the exosomes of MSCs regulates the death and differentiation of neurons in patients with spinal cord injury. Gene Ther 26:491-503.

82. Huang JH, Y Xu, XM Yin and FY Lin. (2020). Exosomes derived from miR-126-modified MSCs promote angiogenesis and neurogenesis and attenuate apoptosis after spinal cord injury in rats. Neuroscience 424:133-145.

83. Liu W, Y Rong, J Wang, Z Zhou, X Ge, C Ji, D Jiang, F Gong, L Li, et al. (2020). Exosome-shuttled miR-216a$5 \mathrm{p}$ from hypoxic preconditioned mesenchymal stem cells repair traumatic spinal cord injury by shifting microglial M1/M2 polarization. J Neuroinflammation 17:47.

84. Li C, X Li, B Zhao and C Wang. (2020). Exosomes derived from miR-544-modified mesenchymal stem cells promote recovery after spinal cord injury. Arch Physiol Biochem 126:369-375.

85. Luo $\mathrm{Y}, \mathrm{T} \mathrm{Xu}, \mathrm{W}$ Liu, Y Rong, J Wang, J Fan, G Yin and W Cai. (2020). Exosomes derived from GIT1overexpressing bone marrow mesenchymal stem cells promote traumatic spinal cord injury recovery in a rat model. Int J Neurosci 1-13. doi:10.1080/00207454.2020 .1734598 .

86. Gu J, ZS Jin, CM Wang, XF Yan, YQ Mao and S Chen. (2020). Bone marrow mesenchymal stem cell-derived exosomes improves spinal cord function after injury in rats by activating autophagy. Drug Des Devel Ther 14: 1621-1631.

87. Li R, K Zhao, Q Ruan, C Meng and F Yin. (2020). Bone marrow mesenchymal stem cell-derived exosomal microRNA-124-3p attenuates neurological damage in spinal cord ischemia-reperfusion injury by downregulating Ern1 and promoting M2 macrophage polarization. Arthritis Res Ther 22:75.

88. Li L, Y Zhang, J Mu, J Chen, C Zhang, H Cao and J Gao. (2020). Transplantation of human mesenchymal stemcell-derived exosomes immobilized in an adhesive hydrogel for effective treatment of spinal cord injury. Nano Lett 20:4298-4305.

89. Oudega M. (2012). Molecular and cellular mechanisms underlying the role of blood vessels in spinal cord injury and repair. Cell Tissue Res 349:269-288.

90. Qu Q, Y Pang, C Zhang, L Liu and Y Bi. (2020). Exosomes derived from human umbilical cord mesenchymal stem cells inhibit vein graft intimal hyperplasia and accelerate reendothelialization by enhancing endothelial function. Stem Cell Res Ther 11:133.

91. Hu G, Li Q, Niu X, Hu B, Liu J, Zhou S, Guo S, Liang H, Zhang C, Wang Y, Deng Z. (2015) Exosomes secreted by human-induced pluripotent stem cell-derived mesenchymal stem cells attenuate limb ischemia by promoting angiogenesis in mice. Stem Cell Res Ther 6:10.

92. Xue C, Y Shen, X Li, B Li, S Zhao, J Gu, Y Chen, B Ma, J Wei, Q Han and RC Zhao. (2018). Exosomes derived from hypoxia-treated human adipose mesenchymal stem cells enhance angiogenesis through the PKA signaling pathway. Stem Cells Dev 27:456-465.

93. Liang X, L Zhang, S Wang, Q Han and RC Zhao. (2016). Exosomes secreted by mesenchymal stem cells promote endothelial cell angiogenesis by transferring miR-125a. J Cell Sci 129:2182-2189.

94. Afshari FT, S Kappagantula and JW Fawcett. (2009). Extrinsic and intrinsic factors controlling axonal regeneration after spinal cord injury. Expert Rev Mol Med 11: e37.

95. Zhang Y, M Chopp, XS Liu, M Katakowski, X Wang, $X$ Tian, D Wu and ZG Zhang. (2017). Exosomes derived from mesenchymal stromal cells promote axonal growth of cortical neurons. Mol Neurobiol 54:26592673.

96. Anderson MA, JE Burda, Y Ren, Y Ao, TM O'Shea, R Kawaguchi, G Coppola, BS Khakh, TJ Deming and MV Sofroniew. (2016). Astrocyte scar formation aids central nervous system axon regeneration. Nature 532:195-200.

97. Tang BL. (2018). Promoting axonal regeneration through exosomes: an update of recent findings on exosomal PTEN and mTOR modifiers. Brain Res Bull 143:123131.

98. Park KK, K Liu, Y Hu, PD Smith, C Wang, B Cai, B Xu, L Connolly, I Kramvis, M Sahin and Z He. (2008). Promoting axon regeneration in the adult CNS by modulation of the PTEN/mTOR pathway. Science 322:963966.

99. David S and A Kroner. (2011). Repertoire of microglial and macrophage responses after spinal cord injury. Nat Rev Neurosci 12:388-399.

100. Kigerl KA, JC Gensel, DP Ankeny, JK Alexander, DJ Donnelly and PG Popovich. (2009). Identification of two distinct macrophage subsets with divergent effects causing either neurotoxicity or regeneration in the injured mouse spinal cord. J Neurosci 29:13435-13444.

101. Domenis R, A Cifu, S Quaglia, C Pistis, M Moretti, A Vicario, PC Parodi, M Fabris, KR Niazi, P Soon-Shiong and F Curcio. (2018). Pro inflammatory stimuli enhance the immunosuppressive functions of adipose mesenchymal stem cells-derived exosomes. Sci Rep 8:13325.

102. Zhou Y, Wu Y, Liu Y, He Z, Zhou S, Wang Q, Li J, Zheng Z, Chen J, et al. (2016). The cross-talk between autophagy and endoplasmic reticulum stress in bloodspinal cord barrier disruption after spinal cord injury. Oncotarget 8:1688-1702.

103. Shao M, M Jin, S Xu, C Zheng, W Zhu, X Ma and F Lv. (2020). Exosomes from long noncoding RNA-Gm37494ADSCs repair spinal cord injury via shifting microglial M1/M2 Polarization. Inflammation 43:1536-1547.

104. Liddelow SA and BA Barres. (2017). Reactive astrocytes: production, function, and therapeutic potential. Immunity 46:957-967.

105. Liddelow SA, KA Guttenplan, LE Clarke, FC Bennett, CJ Bohlen, L Schirmer, ML Bennett, AE Munch, WS Chung, et al. (2017). Neurotoxic reactive astrocytes are induced by activated microglia. Nature 541:481-487.

106. Anderson AJ, Robert S, Huang W, Young W and Cotman CW. (2004). Activation of complement pathways after contusion-induced spinal cord injury. J NEUROTRAUM 21:1831-1846.

107. Fraser DA, M Arora, SS Bohlson, E Lozano and AJ Tenner. (2007). Generation of inhibitory NFkappaB 
complexes and phosphorylated cAMP response elementbinding protein correlates with the anti-inflammatory activity of complement protein $\mathrm{C} 1 \mathrm{q}$ in human monocytes. J Biol Chem 282:7360-7367.

108. Lin Z, H Lin, W Li, Y Huang and H Dai. (2018). Complement component $\mathrm{C} 3$ promotes cerebral ischemia/ reperfusion injury mediated by TLR2/NFkappaB activation in diabetic mice. Neurochem Res 43:1599-1607.

109. Xu L, BOA Botchway, S Zhang, J Zhou and X Liu. (2018). Inhibition of NF-kappaB signaling pathway by resveratrol improves spinal cord injury. Front Neurosci 12:690.

110. Zhou X, X Chu, H Yuan, J Qiu, C Zhao, D Xin, T Li, W Ma, H Wang, Z Wang and D Wang. (2019). Mesenchymal stem cell derived EVs mediate neuroprotection after spinal cord injury in rats via the microRNA21-5p/FasL gene axis. Biomed Pharmacother 115: 108818

111. Hu J, Q Yu, L Xie and H Zhu. (2016). Targeting the blood-spinal cord barrier: a therapeutic approach to spinal cord protection against ischemia-reperfusion injury. Life Sci 158:1-6.

112. Wang J, EE Bonacquisti, AD Brown and J Nguyen. (2020). Boosting the biogenesis and secretion of mesenchymal stem cell-derived exosomes. Cells 9:660.
Address correspondence to: Riyi Shi, PhD

Department of Basic Medical Sciences College of Veterinary Medicine Weldon School of Biomedical Engineering

Purdue University

West Lafayette, IN 47906

USA

E-mail: riyi@purdue.edu

Zhihua Ren, PhD Key Laboratory of Animal Disease and Human Health of Sichuan Province College of Veterinary Medicine Sichuan Agricultural University Yaan 625000

China

E-mail: zhihua_ren@126.com

Received for publication July 30, 2020 Accepted after revision October 12, 2020

Prepublished on Liebert Instant Online October 12, 2020 